\title{
Validity of the Stellenbosch University On-road Assessment
}

\author{
Lizette Swanepoel, B Rad (UP), B OT (UP) \\ Occupational Therapy Manager, USeBenzA Assessment Centre, Division of Occupational Therapy, Stellenbosch University
}

\author{
Sherrilene Classen, BA OT (UFS), PhD OT (Nova Southeastern University), MPH Epidemiology \\ (University of Florida) \\ Post-Doctoral Fellow Public Health / Rehabilitation Sciences (University of Florida)
}

\section{Charlyn Goliath, B OT (SU), M OT (SU)}

Deputy Director: Professional Support, Western Cape Department of Health; Lecturer, Centre for Health Systems and Services Research and Development, Division of Community Health, Stellenbosch University

Background: Internationally, occupational therapists are the professional group called upon to assess fitness to drive. Fitness to drive is assessed through a comprehensive driving evaluation consisting of a clinical battery of tests and an on-road assessment. The on-road assessment is the criterion standard for assessing fitness to drive. Such an assessment has not yet been developed or validated in the South African context.

Purpose: This study empirically quantified the face, content and construct validity of the Stellenbosch University on-road assessment. Methods: Firstly face validity was established using feedback from peer reviewers, secondly, content validity using the ratings of expert reviewers, and thirdly construct validity was established by assessing between group differences in young drivers who drove the road-course. Results: Peer review indicated acceptable face validity. Expert reviewers had an average rater agreement percentage of $94 \%$, indicating favourable content validity. One (of two) on-road outcome measures, the Global Rating Score, discriminated between two groups of drivers, indicating construct validity.

Conclusion: This study introduced the first empirical on-road assessment in the South African context. The findings provided foundational information for occupational therapists interested in assessing in-traffic fitness to drive abilities. Implications for practice, research and policy were discussed.

Key words: Fitness to drive, Measurement, South Africa

\section{INTRODUCTION}

\section{Background}

Traffic injuries were the ninth leading cause of death worldwide in $2004^{\prime}$ and if trends continue it will be the fifth leading cause of injury and mortality in 20I3. In 20I0, the World Health Organisation initiated the Decade of Action on Road Safety², urging international inter-sectoral (transport, health, police, justice, etc.) collaboration to reverse the global trend of increased traffic fatalities.

Within South Africa, the lead agency, the Road Traffic Management Corporation (RTMC), reports 10845 fatal crashes and I 3802 fatalities from I April 2010 to 31 March 20 I I ${ }^{3}$. The factors contributing to road crashes in RSA included human factors, e.g. aggressive and reckless driving patterns; vehicle factors, e.g. worn or damaged tyres; environmental factors, e.g. poor road maintenance. In 2009, human factors were the main contributor of the total number of fatal crashes in South Africa with $84.91 \%$, with other factors being vehicle factors (5.79\%) and the road environment $(9.30 \%)^{4}$. Given these contributory factors to fatal crashes in South Africa, the country has a pressing and critical need to employ a system to identify at-risk drivers on its roads.

\section{LITERATURE REVIEW}

Driving, an instrumental activity of daily living (IADL), is a critical occupation enabling people to take care of personal needs, fulfil roles in society, participate in communities, and obtain access to goods and services ${ }^{5,6,7}$. In South Africa, with limited public transport, driving a vehicle is an advantage for individuals seeking and pursuing employment opportunities ${ }^{8,9}$. However, given the high crash statistics in South Africa, driving must be viewed as a potentially dangerous IADL that can result in adverse outcomes if incongruences exist, within the person (e.g. medical condition impairing judgment and reasoning), the vehicle (e.g. poor roadworthiness) and the environment (e.g. potholes and non-operational traffic signals) ${ }^{7}$.

Occupational therapists are uniquely qualified to make a valuable contribution to the road user safety system of South Africa as they understand the phenomena and interactions between the person, the environment, and the contextual factors ${ }^{10}$. They analyse barriers and understand enhancers of performance in terms of driving " Occupational therapists can apply their training to screen and assess the fitness to drive abilities of clients ${ }^{7,12}$; construct intervention plans to improve driving; adapt activities and/or vehicles; refer clients to other health care professionals; make recommendations; and communicate findings to stakeholders (e.g. medical doctor or licensing agencies). Ultimately, occupational therapists are agents of wellness and health promotion ${ }^{5,6,11,13}$ and injury prevention ${ }^{14}$, and given the critical road safety situation in South Africa, are ideally positioned to help prevent crash related traffic injuries and fatalities.

The assessment of fitness to drive occurs through administering the comprehensive driving evaluation $(C D E)^{15}$, which is also considered the industry gold standard ${ }^{16}$. The comprehensive driving evaluation is typically conducted by an occupational therapist who is a (Certified) Driving Rehabilitation Specialist (OT-CDRS) ${ }^{17}$. The comprehensive driving evaluation consists of a clinical battery of 
visual (and other sensory functions), cognitive, and motor tests, as well as an on-road assessment. Occupational therapy researchers in developed countries have developed batteries of clinical tests for specific populations, including older drivers ${ }^{18,19}$; Parkinson's disease ${ }^{20-22}$; teens with Autism Spectrum Disorder or Attention Deficit Hyperactivity Disorder ${ }^{23}$; Epilepsy ${ }^{24}$; and mild traumatic brain injury $(\mathrm{TBI})^{25}$. The On-Road Assessment (ORA) measures in-traffic fitness to drive abilities in varying environments i.e. parking lots, suburban, city and highways ${ }^{26,27}$. Road courses need to be specifically developed for the context of the geographic region.

Given that occupational therapists can make a substantive contribution to fitness to drive assessments and interventions and that no road course exists in the Western Cape, the main objective of this study was to validate the ORA, designed for the Western Cape.

An ORA must consists of a combination of ${ }^{26-30}$ road conditions (e.g. a variety of roadways); driving conditions (e.g. varying levels of traffic and speed); and an opportunity to observe driving errors (e.g. visual scanning, signalling, vehicle positioning, lane maintenance, speeding and yielding/gap acceptance).

\section{Rational and Significance}

The impetus of this study derives from three fronts: South Africa is one of the leading countries in road traffic injuries and fatalities; prevention of on-road fatalities can take place through valid assessment and intervention; and occupational therapists are the preferred health professionals to address IADL's, including driving, yet no formal assessment for fitness to drive has been validated in South Africa ${ }^{31}$.

\section{Purpose Statement}

This study empirically quantified the validity of an on-road assessment conducted at Stellenbosch University's Usebenza Assessment Centre in the Western Cape.

\section{METHODS}

This study was approved by the Stellenbosch University Health Research Ethics Committee and all participants provided informed consent before they were enrolled in the study.

\section{Study aims}

The study had three aims: To determine the face, content, and construct validity of Stellenbosch University on-road assessment.

\section{Study design}

This study employed a quantitative prospective measurement design, from classical test theory, examining three aspects of validity ${ }^{32,33}$. For face validity peer reviewers ${ }^{33,34}$ provided feedback on the appearance, navigation instructions and the representativeness of the ORA route. For content validity expert reviewers provided feedback, on the representativeness of the individual items of the ORA, to real world driving ${ }^{34,35}$. For construct validity, the researchers employed a known groups methods to discriminate between two independent groups of healthy drivers' outcomes on the ORA ${ }^{33}$.

\section{Population and sampling procedure}

\section{Face validity}

Purposive sampling was used to recruit a convenience sample of ten peer reviewers ${ }^{35}$. Their function was to provide objective feedback on components of the ORA, including the appropriateness (appearance) of the assessment to the concept of fitness to drive, the navigational instructions and the representativeness of the driving conditions in the Western Cape. The inclusion criteria were: having completed at least a Bachelor's degree in Occupational Therapy; registration with the Health Professions Council of South Africa; and having worked, and were still working, in the field of assessment, including administering standardised tools for assessing work, insurance and medico-legal issues, for at least five years. Using local professional databases the first author distributed an e-mail to recruit volunteer occupational therapists who fitted the inclusion criteria. The peer reviewers were contacted via e-mail, briefed on the study background, and after providing consent, enrolled into the study.

\section{Content validity}

Content validity was established through feedback from three inter/ national expert reviewers with experience in driving assessment or measurement theory. Each one of the expert reviewers were known by the researchers and chosen, based on their credibility, inter/national stature and experience in the field of driving rehabilitation or measurement. The expert reviewers were contacted via e-mail, briefed about the study background, and asked to complete a consent form once they have agreed to participate in the study.

\section{Construct validity}

There were two groups of participants for this part of the study. Group one consisted of five conveniently selected healthy novice drivers, ages 18-28, recruited from a local driving school who had undergone driver training in the two months prior to the onset of the study and who were selected by the driving school instructor. Group two consisted of six experienced drivers ages 18-28; with more than two years of driving experience; who were recruited by the first author using contacts within her stakeholder network. The drivers from these two groups were contacted via phone, briefed about the study background, and asked to complete a consent form once they had agreed to participate in the study. The drivers received no payment for participation in the study. Other key participants in the construct validity study were the driving school instructor and a licensing officer from City of Cape Town Department of Traffic. The role of the driving school instructor was to provide the driver with verbal navigational instructions and to ensure the safety of the driver and passengers in the vehicle using the dual brake system in the vehicle. The role of the licensing officer, as an experienced driving assessor, was to assess the drivers using the Stellenbosch University ORA.

\section{Measures: Stellenbosch University On-road Assessment}

The ORA route commenced in the parking lot of the Stellenbosch University Faculty of Medicine and Health Science and progressed over residential and urban areas and included a freeway. Driving occurred in "good" weather conditions, between 9.00 am and 4.00 pm Monday to Friday. The test vehicle was a dual brake manual transmission vehicle from a local driving school. The route covered a distance of $23.8 \mathrm{~km}$ with driving duration being 45 to 55 minutes pending on traffic flow and density. The ORA route included road conditions and driving manoeuvres.

The road conditions included:

* Low and middle socio-economic residential environments with narrow two-way roads and speed restrictions of 40 $-60 \mathrm{~km} / \mathrm{h}$. Environmental characteristics in the low socioeconomic area included low volume motor vehicle traffic; dogs and children present in the road; speed bumps; and vandalised traffic signs. Environmental characteristics in the middle socio-economic area included low motor vehicle traffic, and enhanced controlled intersections such as a raised stop street. Joining the residential and the urban industrial environment (next discussed) was a two-lane traffic circle with four entrances.

* Urban industrial environments and a city centre with wide twoway roads and speed restrictions of $60-70 \mathrm{~km} / \mathrm{hr}$. Environmental characteristics included medium to high volume motor vehicle traffic; pedestrians passing the road without using, or in the absence of pedestrian crossings; vehicles stopping at and entering roadways without using their indicator lights; and a 360 degree curvature in the road. The environment also included a freeway with a dual carriage and speed not exceeding $120 \mathrm{~km} / \mathrm{h}$, therefore accommodating high speed and high volume motor vehicle traffic. Environmental characteristics included slow moving heavy duty tractor-trailer trucks. 
The driving manoeuvres included:

* Nine left and eight right turns at controlled intersections;

$*$ Two left and one right turns at uncontrolled intersections;

* Seventeen straight drives;

* Three lane changes to right and one to left;

* Entering and exiting a I80 degrees traffic circle;

* Pulling away on an incline;

* Merging into high speed traffic; and

* Exiting high speed traffic via a ramp of the freeway

Figure I presents a Google map of the Stellenbosch University ORA. The figure displays the entire route by the eleven road sections (used for content validity rating). The eleven road sections included a variety of road conditions in different environments.

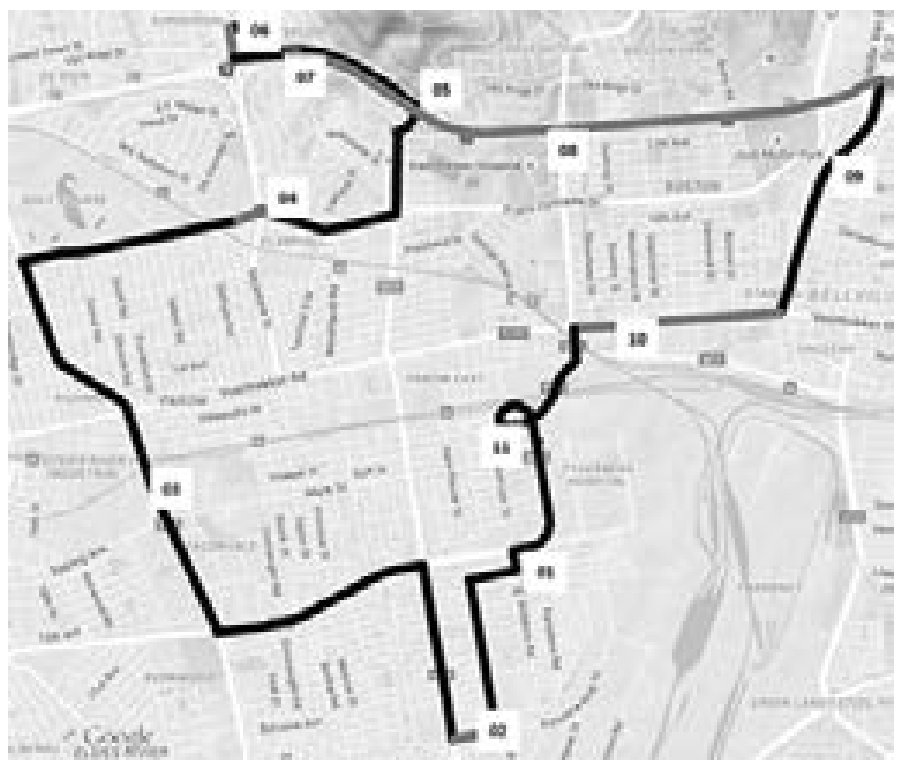

Legend: Road section I: $1.6 \mathrm{~km}$ in a low socio-economic residential environment (urban area),

driving speed not exceeding $40 \mathrm{~km} / \mathrm{h}$; Road section 2: $0.28 \mathrm{~km}$ in an urban area, driving speed not exceeding $60 \mathrm{~km} / \mathrm{h}$; Road section $3: 6.5$ $\mathrm{km}$ in an urban semi-industrial environment, driving speed not exceeding $60 \mathrm{~km} / \mathrm{h}$ to $7 \mathrm{~km} / \mathrm{h}$; Road section 4: $1.8 \mathrm{~km}$ in a semi-industrial environment, driving speed not exceeding 70 $\mathrm{km} / \mathrm{h}$, approaching, entering and exiting a twolane traffic circle; Road section 5: $3.4 \mathrm{~km}$ in a middle socio-economic residential environment, driving speed not exceeding $60 \mathrm{~km} / \mathrm{h}$; Road section 6: $0.1 \mathrm{~km}$ on a bridge connecting the freeway and the residential area, driving speed not exceeding $60 \mathrm{~km} / \mathrm{h}$; Road section 7: $0.2 \mathrm{~km}$ on-ramp onto the freeway; Road section 8: 4.6 $\mathrm{km}$ on a freeway, driving speed not exceeding $120 \mathrm{~km} / \mathrm{h}$ and exiting the freeway onto an off-ramp bridge; Road section $9: 1.9 \mathrm{~km}$ in a semi-industrial urban area, driving speed not exceeding $60 \mathrm{~km} / \mathrm{h}$; Road section 10 : $1.6 \mathrm{~km}$ in a city centre area, driving speed not exceeding $60 \mathrm{~km} / \mathrm{h}$; Road section II: $1.4 \mathrm{~km}$ in a semiindustrial environment following a 360 degrees curve in the road, driving speed not exceeding $60 \mathrm{~km} / \mathrm{h}$.

Figure I: Google map of the

Stellenbosch University on-road route

\section{Scoring}

Existing validated on-road scoring criteria from the University of Florida ORA ${ }^{26}$ informed the construction of the Stellenbosch University ORA scoring form. The route components were accurately included in the sequence that they occur on the route. The driving errors, referred to in the literature review (e.g., visual scanning, vehicle positioning, etc.) were included for each driving manoeuvre on the ORA route. The driving errors were scored using a four level outcome rating scale, i.e.: $3=$ zero errors; 2 = any errors; I = verbal cues were necessary to modify driving behaviour; 0 = physical intervention (e.g., driving school instructor hitting the brake to ensure safety). The driving errors were summed to produce the sum of manoeuvres score (SMS). The Global Rating Scale (GRS) provided an overall interpretation of the driver's performance, with the scale indicating $3=$ fit to drive; 2 = fit to drive with recommendations; I = not fit to drive remediable; $0=$ not fit to drive, unremediable.

\section{Data collection and procedures}

\section{Face validity}

The first author conducted structured interviews with the reviewers ${ }^{35}$, collected their demographic information, and asked their opinions on three structured questions (see Table I below). Peer reviewers provided yes/no responses and/or comments to the questions.

\section{Content validity}

From the expert reviewers, the first author collected demographic information. Using a Visual Analogue Scale (VAS) the expert reviewers rated II items to judge the representativeness of the ORA to real world driving. Reviewer agreement less than $90 \%$ was deemed inadequate and content validity was inferred if the reviewer agreement was $\geq 90 \%^{36}$

\section{Construct validity}

The novice and experienced drivers provided demographic information and participated in the ORA. Using the test-vehicle, the driving school instructor sat in the passenger seat of the vehicle while providing verbal instructions for navigational purposes. The licensing officer was blinded to the status (novice vs. experienced) of the drivers. He scored the fitness to drive abilities of the participants using the ORA scoring form: i.e. 0-3 for driving errors, and by providing a GRS for each driver. The

Table I: Demographic variables and responses on the structured questions from the Peer Reviewers $(\mathbf{N}=10)$

\begin{tabular}{|c|c|c|c|c|c|c|c|}
\hline $\begin{array}{c}\text { Peer } \\
\text { Reviewers } \\
\text { (PR) }\end{array}$ & Age & $\begin{array}{c}\text { Years } \\
\text { Practice }\end{array}$ & $\begin{array}{c}\text { Years of } \\
\text { experience } \\
\text { in } \\
\text { administering } \\
\text { assessments }\end{array}$ & $\begin{array}{c}\text { Experienced } \\
\text { in } \\
\text { administering } \\
\text { driving } \\
\text { assessment }\end{array}$ & Q.1. & Q. 2. & Q.3. \\
\hline PRI & 59 & 39 & 20 & Some & Yes & Yes & $\begin{array}{c}\text { Yes, with } \\
\text { suggestions }\end{array}$ \\
\hline PR2 & 41 & 19 & 19 & Some & Yes & Yes & Yes \\
\hline PR3 & 43 & 17 & 16 & None & Yes & Yes & $\begin{array}{c}\text { Yes, with } \\
\text { suggestions }\end{array}$ \\
\hline PR4 & 46 & 24 & 22 & Some & Yes & Yes & Yes \\
\hline PR5 & 48 & 26 & 26 & Some & Yes & Yes & Yes \\
\hline PR6 & 34 & 13 & 11 & Some & Yes & Yes & $\begin{array}{c}\text { Yes, with } \\
\text { suggestions }\end{array}$ \\
\hline PR7 & 34 & 12 & 9 & None & Yes & Yes & Yes \\
\hline PR8 & 49 & 27 & 27 & Some & Yes & Yes & Yes \\
\hline PR9 & 56 & 33 & 18 & Some & Yes & Yes & Yes \\
\hline PR10 & 40 & 18 & 13 & Some & Yes & Yes & Yes \\
\hline
\end{tabular}

Legend: $\mathrm{Q}=$ Question; Q.I. = Does the ORA appear to assess fitness to drive? Q.2. = Does the navigational instructions on the ORA scoring form appear clear and unambiguous? Q.3. = Does it appear to you that the driving conditions included in the ORA route are representative of driving conditions in the Western Cape? 
first author, not blinded to the status of the participants, sat in the back of the vehicle to ensure appropriate execution of the research protocol.

\section{DATA CAPTURING}

The first author collected and recorded all the validity data. The author devised a Microsoft Excel spreadsheet to capture the responses obtained from the content and construct validity forms. The data were discussed with members of the research team to ensure accuracy; monitored to ensure completed datasets; and stored in a central secure and password protected data repository, located on the server at Stellenbosch University.

\section{Data analysis}

Face validity

The first author integrated the peer review comments into the ORA. Because only minor suggestions (e.g. formatting suggestions) occurred a second round of peer reviews were not indicated.

\section{Content validity}

Based on the feedback of the expert reviewers, the first author calculated their agreement via the average congruency percentage $(\mathrm{ACP})^{36}$. To determine the correlation on the representativeness of the items to real word driving the researchers planned to conduct an intra-class correlation coefficient (ICC) analysis ${ }^{35}$. However, due to the high ACP, an ICC analysis yielded invalid results and the ICC was therefore not included in the final analyses.

\section{Construct validity}

The normality of the data was examined with the Shapiro Wilks test $^{35}$. If the Shapiro Wilks test demonstrated statistical significance, then the non-parametric Wilcoxon rank sum test is indicated for quantifying group differences. The researchers performed basic statistical analyses using Microsoft Excel. All other statistical calculations were performed by the statistician using Stata version I 3 (StataCorp LP). Statistical significance was determined via a two-tailed test of significance with $\mathrm{p} \leq 0.05$.

\section{RESULTS}

\section{Face Validity}

Table I displays the demographics and peer review feedback for each of the ten peer reviewers. The peer reviewers had 9 to 27 years of experience in administering standardised assessments. All peer reviewers were fluent in English and none requested a version of the consent form in any of the other official languages.

As indicated in Table I on page II, the results showed positive responses from all the reviewers on all three questions. Three peer reviewers (PRI, PR3, PR6) proposed inclusion of a township environment, but this recommendation was not integrated as most of the road conditions and driving manoeuvres, that could have occurred within a township environment, were already included in the ORA route. Another peer reviewer (PR4) provided additional feedback on collapsing columns in the ORA form, but that suggestion was neither feasible nor practical and as such this recommendation was also not integrated.

\section{Content Validity}

Three expert reviewers (ages 43-5 I years) completed the review. Their detailed demographic characteristics are displayed in Table II.

Table III indicates almost perfect agreement between the raters (average ratings $\geq 9.4$ ) for all II individual items on the ORA. These findings indicate an ACP higher than the acceptable scale average of $90 \%$. The ICC could not be calculated, due to the small variances (see small standard deviations [SD]), in scores among the different raters.
Table II: Demographic variables for the Expert Reviewers ( $\mathbf{N}=\mathbf{3})$

\begin{tabular}{|l|l|l|l|}
\hline Demographics & $\begin{array}{l}\text { Expert } \\
\text { Reviewer 1 }\end{array}$ & $\begin{array}{l}\text { Expert } \\
\text { Reviewer 2 }\end{array}$ & $\begin{array}{l}\text { Expert } \\
\text { Reviewer 3 }\end{array}$ \\
\hline Age & 51 & 46 & 43 \\
\hline $\begin{array}{l}\text { Gender } \\
\text { Frequency } \\
\text { (percentage) }\end{array}$ & $\begin{array}{l}\text { Female } \\
1(33.3 \%)\end{array}$ & $\begin{array}{l}\text { Female } \\
1(33.3 \%)\end{array}$ & $\begin{array}{l}\text { Male } \\
1(33.3 \%)\end{array}$ \\
\hline $\begin{array}{l}\text { Years' } \\
\text { experience } \\
\text { (field) }\end{array}$ & $\begin{array}{l}17 \text { (driving } \\
\text { assessment) }\end{array}$ & $\begin{array}{l}6 \text { (driving } \\
\text { assessment) }\end{array}$ & $\begin{array}{l}18 \\
\text { (measurement) }\end{array}$ \\
\hline
\end{tabular}

Table III: Ratings of the Expert Reviewers $(\mathbf{N}=3)$ using the Visual Analogue Scale (VAS) to rate II questions pertaining to the Stellenbosch University On-Road Assessment

\begin{tabular}{|l|l|l|l|l|l|}
\hline $\begin{array}{l}\text { Road } \\
\text { Section }\end{array}$ & $\begin{array}{l}\text { Expert } \\
\text { Reviewer } \\
\text { I VAS } \\
\text { Score }\end{array}$ & $\begin{array}{l}\text { Expert } \\
\text { Reviewer } \\
\text { I VAS } \\
\text { Score }\end{array}$ & $\begin{array}{l}\text { Expert } \\
\text { Reviewer } \\
\text { I VAS } \\
\text { Score }\end{array}$ & SD & $\begin{array}{l}\text { Average } \\
\text { VAS Score }\end{array}$ \\
\hline RS I & 9.80 & 9.40 & 10.00 & 0.25 & 9.70 \\
\hline RS 2 & 10.00 & 9.10 & 10.00 & 0.42 & 9.70 \\
\hline RS 3 & 10.00 & 9.40 & 10.00 & 0.28 & 9.80 \\
\hline RS 4 & 10.00 & 9.50 & 10.00 & 0.24 & 9.80 \\
\hline RS 5 & 10.00 & 9.70 & 10.00 & 0.14 & 9.90 \\
\hline RS 6 & 10.00 & 9.60 & 10.00 & 0.19 & 9.90 \\
\hline RS 7 & 9.80 & 9.60 & 10.00 & 0.16 & 9.80 \\
\hline RS 8 & 10.00 & 9.60 & 10.00 & 0.19 & 9.90 \\
\hline RS 9 & 9.80 & 9.50 & 10.00 & 0.21 & 9.80 \\
\hline RS 10 & 10.00 & 9.30 & 10.00 & 0.33 & 9.80 \\
\hline RS 11 & 10.00 & 8.20 & 10.00 & 0.85 & 9.40 \\
\hline
\end{tabular}

Legend: Please see Figure I for a display and description of each of the II road sections.

Figures 2.a. - 2.c. display the scatterplots for the paired reviewer (R) ratings: I-R2, RI-R3 and R2- R3. The scatterplot for each of the reviewer pairs indicated an almost perfect correlation. A second round of reviews was thus not performed.

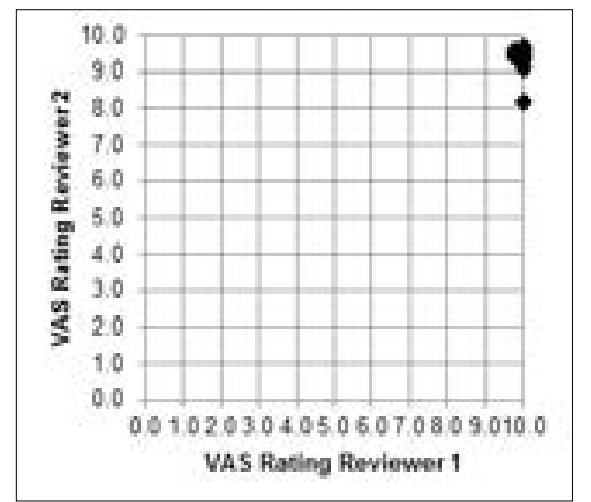

Figure 2a: Scatterplot indicating the VAS score correlations between Expert Reviewer I and 2

\section{Construct Validity}

After conducting the Shapiro-Wilk test the researcher observed that the SMS $(Z=3.17, p<0.001)$ and GRS $(Z=3.43$, $p<0.001)$ data were not normally distributed. Therefore, the researchers analysed the data with the Wilcoxon rank sum test. 


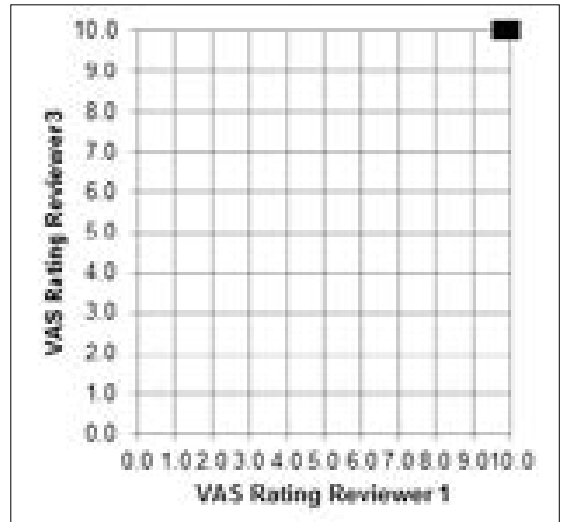

Figure 2b: Scatterplot indicating the VAS score correlations between Expert Reviewer I and 3

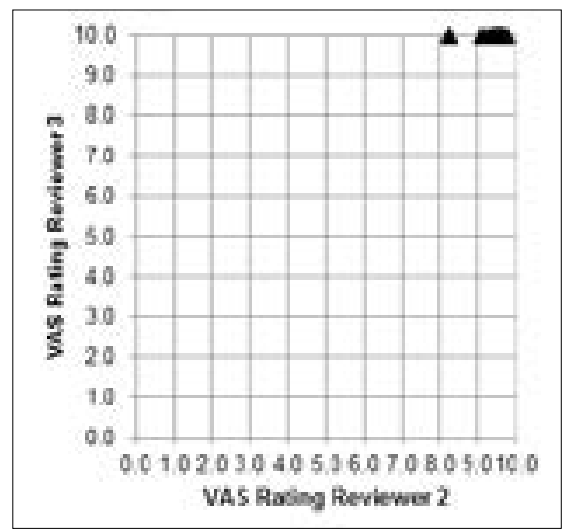

Figure 2c: Scatterplot indicating the VAS score correlations between Expert Reviewer 2 and 3

Table IV displays the descriptive statistics and betweengroup differences for the demographics and driving data for the II experienced and novice drivers. Generally, and compared to the experienced drivers, the novice drivers were younger, had fewer males, fewer whites, less schooling, and fewer English speaking participants. Overall, compared to the experienced drivers, and with the exception of signalling, the novice drivers made more driving errors. The between-group differences for the demographics indicated a statistical significant difference for age (experienced drivers were older). No statistically significant between-group differences were detected for driving errors.

Table $V$ indicates the between-group differences for the dependent variables (SMS, GRS) in the experienced and novice drivers $(N=I I)$. Despite the higher mean SMS for experienced drivers, the researchers did not observe a statistically significant difference between the SMS of experienced and novice drivers. However, a statistical significant difference between the GRS of experienced and novice drivers were observed. Based on the GRS, the Stellenbosch University ORA distinguished between novice and experienced drivers and therefore we can infer partial construct validity.

\section{DISCUSSION}

This study established face, content and construct validity of the conceptually developed Stellenbosch University ORA.

The peer reviewers, involved in face validity, provided positive feedback on all three questions to assess the characteristics of the Stellenbosch University ORA. Therefore, the findings suggested favourable face validity. Face validity is extremely important if fitness to drive, and ultimately licensing decisions, are to be made.
Table IV: Descriptive statistics and between group differences for demographics and driving data for experienced and novice drivers $(\mathbf{N}=\mathbf{I})$

\begin{tabular}{|c|c|c|c|c|c|}
\hline \multicolumn{2}{|c|}{ Independent variables } & $\begin{array}{l}\text { Experienced } \\
\text { Drivers } \\
(n=6)\end{array}$ & $\begin{array}{l}\text { Novice } \\
\text { Drivers } \\
(n=5)\end{array}$ & $\begin{array}{l}\text { Test } \\
\text { statistic }\end{array}$ & P-value \\
\hline \multicolumn{2}{|l|}{ Age: Mean (SD) } & $24.3(2.58)$ & $19.2(1.10)$ & $-2.77^{a}$ & $0.005^{*}$ \\
\hline \multirow{2}{*}{$\begin{array}{l}\text { Gender: } \\
\text { Frequency, } \\
\text { (percentage) }\end{array}$} & Male & $2(18.18 \%)$ & $0(0)$ & \multirow{2}{*}{$2.037^{b}$} & \multirow{2}{*}{0.455} \\
\hline & Female & $4(36.36 \%)$ & $5(45.46 \%)$ & & \\
\hline \multirow{3}{*}{$\begin{array}{l}\text { Race: Frequency } \\
\text { (percentage) }\end{array}$} & Black & $0(0 \%)$ & I (9.09\%) & \multirow{3}{*}{$1.42^{b}$} & \multirow{3}{*}{0.70} \\
\hline & Colour & I (9.09\%) & I (9.09\%) & & \\
\hline & White & $5(45.46 \%)$ & $3(27.27 \%)$ & & \\
\hline \multicolumn{2}{|c|}{$\begin{array}{l}\text { Years of owing a driver's } \\
\text { license: Mean (SD) }\end{array}$} & $4.33(1.25)$ & $0(0)$ & NA & NA \\
\hline \multirow{2}{*}{$\begin{array}{l}\text { Schooling: } \\
\text { Frequency } \\
\text { (percentage) }\end{array}$} & $\begin{array}{l}10 \text { to } 12 \\
\text { years }\end{array}$ & I (9.09\%) & $4(36.36 \%)$ & \multirow[t]{2}{*}{$4.4 \mathrm{I}^{\mathrm{b}}$} & \multirow[t]{2}{*}{0.08} \\
\hline & $\begin{array}{l}>12 \\
\text { years }\end{array}$ & $5(45.46 \%)$ & I (9.09\%) & & \\
\hline \multirow{2}{*}{$\begin{array}{l}\text { Language: } \\
\text { Frequency } \\
\text { (percentage) }\end{array}$} & English & $5(45.46 \%)$ & $3(27.27 \%)$ & \multirow[b]{2}{*}{$2.2 I^{b}$} & \multirow[b]{2}{*}{0.14} \\
\hline & Afrikaans & I (9.09\%) & $2(18.18 \%)$ & & \\
\hline \multicolumn{6}{|c|}{ Driving Errors (Mean, SD) } \\
\hline \multicolumn{2}{|l|}{ Visual Scanning } & $13.33(3.77)$ & $14.00(6.81)$ & $0.27^{a}$ & 0.78 \\
\hline \multicolumn{2}{|l|}{ Signalling } & $1.33(1.11)$ & $1.20(2.40)$ & $-0.998^{a}$ & 0.32 \\
\hline \multicolumn{2}{|l|}{ Vehicle Positioning } & $0.00(0.00)$ & $1.20(2.40)$ & NA & NA \\
\hline \multicolumn{2}{|l|}{ Speeding } & $1.33(1.60)$ & $3.20(3.06)$ & $0.86^{a}$ & 0.30 \\
\hline \multicolumn{2}{|l|}{ Lane Maintenance } & $0.00(0.00)$ & $3.80(2.86)$ & NA & NA \\
\hline \multicolumn{2}{|c|}{ Adjustment to Stimuli } & $0.33(0.47)$ & $1.00(1.26)$ & $0.64^{a}$ & 0.52 \\
\hline \multicolumn{2}{|l|}{ Yielding } & $0.00(0.00)$ & $0.40(0.80)$ & NA & NA \\
\hline \multicolumn{2}{|l|}{ Gap Acceptance } & $0.00(0.00)$ & $0.20(0.40)$ & NA & NA \\
\hline
\end{tabular}

Legend: $a=$ Wilcoxon rank sum test; $b=$ Fisher's exact test (cells with less than 5 data points exist); $*$ statistical significance for $\mathrm{p} \leq 0.05$; NA $=$ statistics could not be calculated because of 0 means values

Table V: Between group differences for driving outcomes in experienced and novice drivers $(\mathbf{N}=I I)$

\begin{tabular}{|l|c|c|c|c|}
\hline $\begin{array}{l}\text { Dependent } \\
\text { variable }\end{array}$ & $\begin{array}{c}\text { Experienced } \\
\text { drivers }(\mathrm{n}=6)\end{array}$ & $\begin{array}{c}\text { Novice } \\
\text { drivers }(\mathrm{n}=5)\end{array}$ & $\begin{array}{c}\text { Test statistic } \\
(\mathrm{Z})\end{array}$ & $\begin{array}{c}\text { Statistical } \\
\text { significance } \\
(\mathrm{p} \text {-value })\end{array}$ \\
\hline $\begin{array}{l}\text { Sum of } \\
\begin{array}{l}\text { Manoeuvres } \\
\text { Score: Mean } \\
(\text { SD) }\end{array}\end{array}$ & $\mathrm{II} 4.00(6.73)$ & $\begin{array}{c}101.80 \\
(21.55)\end{array}$ & -0.46 & 0.65 \\
\hline $\begin{array}{l}\text { Global Rating } \\
\text { Scale: Mode }\end{array}$ & 3 & $3 ; 2$ & -2.10 & $0.04 *$ \\
\hline
\end{tabular}

Legend: * indicates statistical significance for $p<0.05 ; Z$ values indicted the statistic for the Wilcoxon rank sum test.

Participants undergoing the Stellenbosch University ORA may relate to being assessed in real world conditions, i.e. in a real vehicle and in real-time traffic, and as such may be more amenable to accepting the final fitness to drive decisions.

Even though face validity is essential for validity studies, it is not sufficient ${ }^{35}$. Therefore the content validity testing in this study invited the scrutiny of expert reviewers ${ }^{36,37}$. The findings suggested excellent agreement among the expert raters. Similarly, the ratings also correlated with the representativeness of the individual items of the Stellenbosch University ORA to real world driving. The correlations were so high that insufficient variance existed for calculating ICC 
values. Thus, the high percentage of agreement ( $\geq 94 \%)$ among the expert raters, coupled with the high level of correlation among the raters in the representativeness of the individual items, indicated content validity of the Stellenbosch University ORA.

Construct validity invites empirical methods to further improve upon the accuracy of the assessment too ${ }^{35}$. As such, the descriptive findings suggested that although mean group differences existed in the demographics, only age (experienced drivers were older) was statistically significant. Likewise, mean group differences existed in the driving errors (experienced driving making fewer driving errors, except for signalling), but none indicated statistical significance. The absence of statistical significant differences may be explained by the small sample sizes and thus the emergence of a Type 2 error ${ }^{35}$. That means, if a difference between the groups really existed, we had too few subjects to detect such a difference. As such the research team cannot make definitive conclusions on the group differences (other than those indicated by the means) for demographics or driving errors.

The team employed inferential statistics to examine the two outcome measures, i.e. SMS and the GRS. The SMS is a summary score of the eight driving errors ${ }^{26}$. Based on the eight levels of this outcome variable, and given the study's small sample size, no between-group differences emerged. However, the GRS which had only four outcome levels (more likely to obtain meaningful differences in small samples), did show statistically significantly differences between the novice and experienced drivers. Based on the GRS findings, partial construct validity can be inferred for the Stellenbosch University ORA.

In summary, classical test theory proposes that assessment instruments should be validated to (I) measure what it claims to measure, (2) measure the specific construct accurately and objectively, and (3) prevent bias in the assessor ${ }^{32}$. The construct of fitness to drive ${ }^{12}$ encompasses real-world driving in a real world in-traffic environment and the Stellenbosch University ORA was developed accordingly ${ }^{26-29}$. We surmised that inclusion of these components in developing the Stellenbosch University ORA resulted in peer and expert reviewers providing empirical support for face and content validity of the instrument. Likewise, findings from our betweengroup differences partially supported construct validity of the ORA.

The limitations of this study pertained to the small sample sizes used in the content (three expert reviewers) and construct validity (eleven drivers) studies. First, a larger number of expert reviewers might have provided responses resulting in more variant ratings. As such, more rigorous statistical procedures could have been employed (e.g. the content validity index, intra class correlation coefficient analysis) to yield stronger empirical support for the content validity of this study ${ }^{34,38}$. Second, due to the small sample of driving participants the findings can only be generalised to young drivers (ages 18 to 28), and to the specific road conditions and driving manoeuvres apparent in the Stellenbosch University ORA. As mentioned previously, Type 2 error likely obstructed our attempt to establish construct validity for the SMS outcome.

The strengths of this study included acceptable face and content validity, and the GRS indicated (partial) construct validity for the Stellenbosch ORA. As such, this study provided first steps towards empirically validating an ORA in South Africa. The study also laid the foundation for clinical practitioners to understand the components of an ORA as they wish to develop their own context specific onroad assessments.

The implications for occupational therapy practice are several. Driving rehabilitation is a complex, yet emerging specialty in occupational therapy. Little education in driving rehabilitation exists in current occupational therapy curricula and the authors invite occupational therapy practitioners to consider pursuing post-professional training in driving assessment and intervention (information available from sclassen@uwo.ca). Moreover, until now, occupational therapists in South Africa have had no local evidence-based research to guide clinical practice. This study introduced the components of road course development, the key construct of fitness to drive, its related concepts (e.g. driving errors, driving conditions), and driving-related vocabulary to better describe driving related issues.

The research team is planning focussed research studies to address the limitations of this current study. Specifically, we will determine construct validity in a well-powered sample, representing different at-risk populations with medical conditions. To enhance the psychometrics of the Stellenbosch University ORA, reliability studies, specifically intra-rater (examining consistency ratings of trainee raters) and inter-rater reliability (examining consistency ratings of trained occupational therapists) are indispensable ${ }^{35}$. Additionally, the ORA as the criterion standard for fitness to drive assessments ${ }^{7,16,39}$, provides opportunities for validating clinical batteries of tests, for at-risk populations, (e.g. older or neurologically impaired drivers) that may be predictive of real-world driving outcomes within the South African context.

This study has implications for policy. Conversations occurring during the course of the study indicated a pressing need to compliment the current Department of Traffic licensing procedures with fitness to drive assessments. After conducting the ORA, a licensing officer indicated that he gained insight into driving behaviours indicative of functional impairment, and as such realised the importance of referral to occupational therapists. A plausible opportunity is emerging for occupational therapists to partner with licensing officers, in conducting fitness to drive assessments, or to receive referrals of individuals with functional limitations and as such influence licensing policy.

\section{CONCLUSION}

This study is novel in that it is the first ORA developed and (partially) validated within the South African context. The findings provided foundational information for occupational therapists (and other health care professionals) interested in assessing in-traffic fitness to drive abilities. South African occupational therapists are facing a role emerging opportunity in the field of driving rehabilitation. As such, validated new measures have the potential to promote the clinical practice skills underlying driving assessment and intervention, enhance the evidence base of driving, and advocate for partnership with licensing agencies.

\section{ACKNOWLEDGEMENTS}

The Canada-Africa Research Exchange Grants 06/0I/20I405/3 I/20 I6 (PI: Classen) funded this research collaboration and manuscript preparation. The Stellenbosch University Masters in Occupational Therapy programme and the University of Western Ontario's i-Mobile Research Lab provided the infrastructure for completing this article. Mr. Michael McCaul provided statistical consultation and data analysis. The peer reviewers and expert reviewers, Mr. F. Isaacs from the $\mathrm{He}$ and She Driving School, Mr. G. Koen from Belrail Department of Traffic, and the volunteer drivers, contributed richly to this study.

\section{REFERENCES}

I. World Health Organisation. Global Status Report on Road Safety: Time for Action. 2009.

2. World Health Organisation. Global Plan for the Decade of Action for Road Safety, 20II - 2020. 201 I.

3. Road Traffic Management Corporation. Road Traffic Report: 31 March, 20II.

4. Road Traffic Management Corporation. Road Traffic Report for the Calender Year, 2009 : 47.

5. World Federation of Occupational Therapists. Definitions of Occupational Therapy. 20 I I; Available at: http://www.wfot.org/aboutus/ aboutoccupationaltherapy/definitionofoccupationaltherapy.aspx. (II/I2/20I3).

6. Classen S. From the Desk of the Guest Editor: Special Issue on Older Driver Safety and Community Mobility. American Journal of Occupational Therapy, 2010; 64(2): 211 .

7. Stedman TL, editor. Stedman's Medical Dictionary for the Health Professions and Nursing. $7^{\text {th }}$ ed. Sydney: Lippencot, Williams \& 
Wilkins, 20I I.

8. QuadPara Association of SA. Driving Ambitions Home Page. http:// www.drivingambitions.co.za/index.html. (25/08/20I3).

9. Law M, Baptiste S, McColl M, Opzoomer A, Polatajko H, Pollock N. The Canadian Occupational Performance Measure: An Outcome Measure for Occupational Therapy. Canadian Journal of Occupational Therapy, 1990; 57(2): 82 - 87.

10. Christiansen C, Baum C. Occupational Therapy: Performance, Participation and Well-being. $3^{\text {rd }}$ ed. Thorofare: Slack; 2004.

I I. Brouwer WH, Ponds RW. Driving Competence in Older Drivers. Disability and Rehabilitation, 1994; 16: 149-161.

12. [Unpublished document]. Regulations Defining the Scope of the Profession of Occupational Therapy made in terms of the Health Professions Act, 1974 (Act No. 56 of 1974).

13. Tucker P, Vanderloo L, Irwin J, Mandich A, Bossers A. Exploring the Nexus Between Health Promotion and Occupational Therapy: Synergies and Similarities. Canadian Journal of Occupational Therapy, 2014; 8I(3): I83-193.

14. Scaffa M, Reitz M, Pizzi M. Occupational Therapy in the Promotion of Health and Wellness. $2^{\text {nd }}$ ed. Philadelphia: F A Davis Company, 2014.

15. McGuire M, Davis E. Driving and Community Mobility: Occupational Therapy Strategies Accross the Lifespan. Ist ed. Bethesda: AOTA Press, 2012.

16. Di Stefano M, Macdonald W. Driver rehabilitation and community principles and practice. In: Pellerito J, editor. On-the-road evaluation of driving performance. St. Louis: Elsevier/Mosby; 2005: 255-274.

17. The Association for Driver Rehabilitation Specialists: http://www. aded.net/?page =210. $(8 / 12 / 2014)$.

18. Stav WB, Justiss MD, McCarthy DP, Mann WC, Lanford DN. Predictability of Clinical Assessments for Driving Performance. Journal of Safety Research, 2008; 39( I-7): 102-108.

19. Kay L, Bundy A, Clemson L, Jolly N. Validity and Reliability of the ON-road Driving Assessment with Senior Drivers. Accident, Analysis and Prevention, 2008; 40(2): 75I-759.

20. Classen S, Brumback B, Monahan M, Malaty I, Rodriguez R, Okun $M$, et al. Driving Errors in Parkinson's Disease: Moving Closer to Predicting On-road Outcomes. American Journal of Occupational Therapy, 2014; 68(I): 77-85.

21. Devos H, Vandenberghe W, Nieuwboer A, Tant M, Baten G, De Weerdt W. Predictors of Fitness to Drive in People with Parkinson's Disease. Neurology, 2007; 69(14): I434- I44I.

22. Uc E, Rizzo M, Johnson A, Emerson J, Liu D, Mills E, et al. Real-life Driving Outcomes in Parkinson's Disease. Neurology, 201 I; 76(22): 1894-1902.

23. Classen S, Monahan M, Brown KE, Hernandez S. Driving Indicators in Teens with Attention Deficit Hyperactivity and/or Autism Disorder. Canadian Journal of Occupational Therapy, 20 I 3; 80(5): 274-283.

24. Crizzle A, Classen S, Winter SM, Silver WE, LaFranca C, Eisenschenk S. Associations Between Clinical Tests and Simulated Driving Performance in Persons with Epilepsy. Epilepsy and Behaviour, 2012; 23: 24 I-246.

25. Classen S, Levy C, Meyer D, Bewernitz M, Lanford DN, Mann WC. Simulated Driving Performance of Combat Veterans with Mild Traumatic Brain Injury and Post-traumatic Stress Disorder: A Pilot Study. American Journal of Occupational Therapy, 20 I I ; 65(4): 419-427.

26. Justiss MD. Development of a behind-the-wheel driving performance assessment for older adults (PhD Thesis). Florida: University of Florida, 2005.

27. Odenheimer G, Beaudet M, Jette A, Albert M, Grande L, Minaker K. Performance-Based Driving Evaluation of the Elderly Driver: safety, reliability, and Validity. Journal of Gerontology, 1994; Vol 49(4): MI53-MI59.

28. Korner-Bitensky N, Gèlinas I, Man-Son-Hing M, Marshall S. Recommendations of the Canadian Consensus Conference on Driving Evaluation in Older Drivers. Physical \& Occupational Therapy in Geriatrics, 2005; 23(2/3): 123-144.

29. Patomella A, Tahm K, Johansson K, Kottorp A. P-Drive on-road: Internal scale validity and reliability of an assessment of on-road driving performance in people with neurological disorders. Scandinavian lournal of Occupational Therapy, 2010; 17: 86-93.
30. Michon JA. A critical View of Driver behaviour Models: What Do We Know, What Should We Do?. In: Evans L, Schwing RC, editors. Human Behaviour and Traffic Safety. Ist ed. New York: Plenum Press; 1985: 485-520.

31. Classen S, Schechtman O, Awadzi KD, Joo Y, Lanford DN. Traffic Violations Versus Driving Errors of Older Adults: Informing Clinical Practice. American Journal of Occupational Therapy, 2010; 64(2): 233-24I.

32. Streiner D, Norman G. Health measurement scales: a practical guide to their development. $2^{\text {nd }}$ ed. New York: Oxford University Press, 1998.

33. Kielhofner G. Research in Occupational Therapy: Methods of Inquiry for Enhancing Practice. Ist ed. Philadelphia: F.A. Davis Company, 2006.

34. Classen S, Winter SM, Velozo CA, Bèdard M, Lanford DN, Brumback $B$, et al. Item Development and Validity Testing for a Self- and Proxy Report: The Safe Driving Behavior Measure. American Journal of Occupational Therapy, 2010; 64(2): 296-305.

35. Portney L, Watkins M. Foundations of Clinical Research: Applications to Practice. $3^{\text {rd }}$ ed. New Jersey: Pearson Education Inc, 2009.

36. Polit DF, Beck CT. The Content Validity Index: Are You Sure You Know What's Being Reported? Critique and Recommendations. Research in Nursing and Health, 2006; 29: 489-497.

37. Davis L. Instrument Review: Getting the Most From Your Panel of Experts. Applied Nursing Research, 1992; 5: 194- 197.

38. McGartland Rubio D, Berg-Weger M, Tebb SS, Lee ES, Rauch S. Objectifying content validity: Conducting a content validity study in social work research. Social Work Research, 2003; 27(2): 94- 104.

39. South African Institute for Driving Instructors (SAIDI): Legislation. http://www.saidi.co.za/index.php?page=const. $31 / 07 / 2013$.

\section{Corresponding Author}

\section{Lizette Swanepoel}

lizswan@sun.ac.za

P.O. Box 212 ,

Stellenbosch,

7599 